\title{
Comorbidity Profiles among Obese-Diabetic End- Stage Renal Disease Patients: Data from REIN Registry of PACA Region of France
}

This article was published in the following Dove Press journal: Diabetes, Metabolic Syndrome and Obesity: Targets and Therapy

\author{
Asmatullah Kakar' \\ Yosra Mouelhi' \\ Anderson Loundou' \\ Adeline Crémades' \\ Stephanie Gentile $\mathbb{D}^{1,2}$ \\ 'Aix Marseille University School of \\ Medicine - La Timone Medical Campus, \\ EA 3279: CEReSS - Health Service \\ Research and Quality of Life Center, \\ Marseille, France; ${ }^{2}$ Assistance Publique, \\ Hôpitaux de Marseille (AP-HM), \\ Marseille, France
}

Correspondence: Asmatullah Kakar Aix Marseille University School of Medicine - La Timone Medical Campus, EA 3279: CEReSS - Health Service Research and Quality of Life Center, 27 Boulevard Jean Moulin, Marseille, I3005, France

Tel +33-4 91324470

$\mathrm{Fax}+33(0) 491384482$

Email asmatullah.kakar@gmail.com
Introduction: The proportion of new dialysis patients with comorbidities increased by an average of 5.6\% per year in the Provence-Alpes-Côte d'Azur (PACA) region, with major increases in obese, cancer, and diabetic patients. This study aimed to describe comorbidity profiles among obese-diabetic end-stage renal disease (ESRD) patients in the Renal Epidemiology and Information Network (REIN) registry of the PACA region of France on December 31, 2018.

Methods: Data for this retrospective cross-sectional study were retrieved from the REIN registry of the PACA region. Data were analyzed using two models. Firstly, the ESRD patients were divided into two groups and binary logistic regression model used for the analysis of the data. Secondly, ESRD patients were divided into four groups and multinomial logistic regression model used. Univariate analysis was performed for group comparison using $\mathrm{x}^{2}$ and $t$-tests, while binary logistic and multinomial logistic regression models were used for multivariate analysis to derive ORs and 95\% CIs.

Results: Among the 4,491 ESRD patients in this study, 623 were obese-diabetic and 3,868 nonobese-nondiabetic and obese only/ diabetic only. Obese-diabetic ESRD patients were younger ( $<75$ years, OR 0.46, $p<0.001$ ), smoked less (OR $0.51, p<0.001$ ), were mainly dialyzed at centers (OR 1.29, $p=0.014$ ), and less likely to be on the renal transplant waiting list (OR 0.46, $p<0.001$ ) compared to the other group. Obese-diabetic ESRD patients also had more comorbidities, including cardiovascular diseases (OR 1.38, $p=0.028$ ), coronary insufficiency (OR 1.49, $p=0.001$ ) and chronic obstructive pulmonary disease (OR 1.75, $p<0.001$ ), but had fewer cases of cancer (OR $0.68, p=0.024$ ) compare to the other group.

Conclusion: Obese-diabetic patients with ESRD have many specific characteristics. These patients were younger, but had more cardiovascular comorbidities and were less likely to be on the waiting list for transplantation. They should receive special attention and be the subject of prevention and therapeutic education.

Keywords: comorbidities, ESRD, CKD, REIN, obesity, diabetes

\section{Introduction}

In France in 2018, 11,343 new patients began renal replacement therapy (RRT), and as of December 3189,692 patients were being treated. ${ }^{1}$ The incidence of end-stage renal disease (ESRD) is increasing, and consequently there has been a steady increase in the number of patients on RRT. Furthermore, obesity, diabetes, and hypertension are the main causes of the increase in chronic kidney disease (CKD) and ESRD incidence, and thus considered the leading health problems. ${ }^{2-6}$ Many epidemiological studies have found that age, ${ }^{7}$ diabetes mellitus, ${ }^{8,9}$ 
hypertension, ${ }^{10,11}$ obesity, ${ }^{12,13}$ and smoking ${ }^{14-16}$ are notable risk factors of kidney dysfunction and associated RD.

Having two or more morbidities is usually termed multimorbidity, and thus this definition can be applied to ESRD patients who possess one or more comorbidities. ${ }^{17}$ It has been found that the proportion of new dialysis patients with comorbidities increased by an average of $5.6 \%$ per year, with major increases in obese, cancer, and diabetic patients. ${ }^{18}$ Comorbidities are a vital consideration, because they can impact on quality of life, treatment burden, management of medication, and survival. ${ }^{19-21}$ As disease load increases (because of complexity, severity, or number of conditions), so does the effort needed of patients and their ability to respond may suffer, resulting in poor outcomes, as described in other chronic conditions, such as stroke. ${ }^{22}$

It has been reported that in addition to comorbidities, the patient's age also plays a vital role in enhancing the functional status of kidneys. ${ }^{23}$ Evidence indicates that timely intervention in the early stage of CKD, may slow its advancement into ESRD or entirely stop progression of the disease. ${ }^{24}$ This requires the utilization of specific medications to improve the life expectancy of these patients and minimize the progression of CKD into ESRD. ${ }^{25,26}$

A majority of the studies on this topic have assessed comorbidity profiles among CKD and ESRD patients only. ${ }^{27-30}$ However, this novel study provides an insight into the associated comorbidities with ESRD patients who were both obese and diabetic.

The aim of this study was thus to describe comorbidity profiles among obese-diabetic ESRD patients in the Renal Epidemiology and Information Network (REIN) registry of the Provence-Alpes-Côte d'Azur (PACA) region of France. This will also build awareness of the load of comorbidities in obese-diabetic ESRD patients on dialysis.

\section{Methods}

\section{Study Design and Population}

A retrospective cross-sectional study was designed to investigate comorbidity profiles of obese-diabetic ESRD patients on RRT, i.e, on dialysis (hemodialysis or peritoneal dialysis). We included all ESRD patients (children and adults) who were obese, diabetic, nonobese, and nondiabetic and receiving RRT, no matter what their place of residence was. Data on these patients were taken from the
PACA REIN registry to December 31, 2018. We used two models for analysis of the data.

1. For the first model, we divided the ESRD patients into two groups:

- obese-diabetic, comprised only those who were both obese and diabetic

- nonobese-nondiabetic, obese only, and diabetic only consisted of those who were obese or diabetic only and those who were both nonobese and nondiabetic.

To constitute these 2 groups, we placed obese patients (BMI $\geq 30$ ) who also had diabetes in the first group and the rest in the second group.

1. For the second model, we divided the ESRD patients into four groups:

- obese-diabetic

- nonobese-nondiabetic

- obese only

- diabetic only.

All mandatory data were gathered and there were none missing. Information relating to comorbidities, BMI, mode of dialysis, and others were retrieved from the patient file completed and updated by the nephrologist who was treating the patients.

\section{Data Sources}

Data of ESRD patients on dialysis come from the French REIN registry. ${ }^{31,32}$ The model of the REIN registry, its functioning, and quality control has been described by Couchoud et al in detail. ${ }^{32}$

\section{Data Collection}

Data collected from patient files were saved in the computer system of REIN (Diadem) by nephrologists or by clinical research assistants affiliated with REIN. ${ }^{31}$ Data updates and quality control were carried out by clinical research assistants each year on the anniversary of the first dialysis. Accuracy was systematically checked for areas considered essential, ie, place of residence, RRT beginning date, primary $\mathrm{KD}$, comorbidities, modality of treatment, change in dialysis site, change in dialysis type, and death. ${ }^{31,32}$ 


\section{Data Selection}

We identified comorbidities for observation if they were of sufficient severity in obese-diabetic ESRD patients. These were chronic obstructive pulmonary disease (COPD), cancer, hepatitis $\mathrm{B}$, hepatitis $\mathrm{C}$, arteritis of the lower limbs, coronary insufficiency, cardiac insufficiency, myocardial infarction, cerebrovascular accident, transient ischemic attack, cardiac arrhythmia, and cirrhosis.

To characterize elderly subjects, we set an age of $\geq 75$ years to know which group contained younger ESRD patients. For cardiovascular disease (CVD) comorbidity, we set a criterion of having at least one of myocardial infarction, cardiac insufficiency, cerebrovascular disease, dysrhythmia, coronary insufficiency, and transient ischemic attack.

\section{Data Analysis}

We used SPSS 20.0 (IBM, Armonk, NY, USA) for statistical analysis. Categorical data are presented as number of patients and percentage, while quantitative data are presented as mean $\pm \mathrm{SD}$.

Univariate analysis was performed for group comparison using $\mathrm{x} 2$ tests for categorical variables and $t$-tests for quantitative variables.

For the first analysis, we used binary logistic regression to compare two groups, ie, obese-diabetic with nonobesenondiabetic, obese only, and diabetic only, in term of associated comorbidities.

For the second analysis, we used multinomial logistic regression to compare four groups, ie, obese-diabetic with nonobese-nondiabetic, diabetic only, and obese only.

All variables with $p<0.2$ in the univariate model were then included as candidate variables in multivariate analysis. We then performed backward elimination for the purpose of conserving only variables with $p<0.05$ in the final model. Adjusted ORsand 95\% CI were calculated.

\section{Results}

\section{Descriptive Characteristics of the Two Groups}

A total of 4,491 ESRD patients (obese and diabetic 623, obese only 292 , diabetes only 1,330 , neither obese nor diabetic 2,246) were present in the REIN registry on December 31, 2018, and all were included in this study. Table 1 presents the univariate analysis for obese-diabetic ESRD patients present in the REIN registry.
A majority of the obese-diabetic patients were male (55.1\%), and $36.1 \%$ were aged $\geq 75$ years compared to $45.6 \%(p<0.001)$ in the other group, indicating that they were younger than the other group. Obese-diabetic patients also had low mean dialysis duration (3.91 \pm 4.2 , $p<0.001)$ than the other group (Table 1).

Fewer obese-diabetic patients were on the renal transplant waiting list (8.8\%) than the other group (14.6\%). The main reason for this was medical contraindications $(p<0.001)$.

Furthermore, the obese-diabetic group was dialyzed more at centers $(67.9 \%, p<0.001)$, smoked less $(8.7 \%$, $p<0.05$ ), and had more CVDs (at least one, 74.6\%, $p<0.001)$, COPD $(19.9 \%, p<0.001)$, coronary insufficiency disease $(43.7 \%, p<0.001)$, and arteritis of lower limbs $(33.7 \%, p<0.001)$, but had fewer cases of cancer $(7.9 \%$, $p<0.05$ ) than the other group (Table 1).

\section{Comorbidity Profiles and Other Characteristics among Obese-Diabetic ESRD Patients}

Table 2 presents the outcomes through our first model: binary logistic regression analysis of comorbidities and other variables (medical and demographic).

Only four comorbidities reached significance:CVD (OR 1.38, $p<0.05$ ), coronary insufficiency (OR 1.49, $p<0.05$ ), COPD (OR 1.75, $p<0.001$ ), and cancer (OR $0.68, p<0.05)$. This indicated that the obese-diabetic patients had more CVDs, cases of coronary insufficiency, and COPD, but fewer cases of cancer than the other group (Table 2).

Apart from diseases, certain variables were also associated with obese-diabeticpatients on RRT. These variables were significant on multivariate analysis. These patients were younger than the other group (OR 0.46, $p<0.001$ ). Dialysis was mainly at centers (OR 1.29, $\mathrm{p}<0.05)$, which indicates that the obese-diabetic ESRD patients were dialyzed more at centers than the other group. Furthermore, the obese-diabetic patients were less smoking than the other group (OR 0.51, $p<0.001$ ).

ESRD patients on RRT who require renal transplantation are normally kept on the renal transplant waiting list. Fewer obese-diabetic patients were on the waiting list than the other group (OR 0.46, $p<0.001$ ). The major fact behind this is that there is an increased risk of graft rejection in obese patients than nonobese patients (Table 2). 
Table I Characteristics of ESRD patients on REIN registry $(n=4,491)$

\begin{tabular}{|c|c|c|c|}
\hline \multirow[t]{2}{*}{ Charecteristics } & $\begin{array}{l}\text { Group I, } \\
\text { obese-diabetic }\end{array}$ & $\begin{array}{l}\text { Group } 2 \text {, } \\
\text { nonobese-nondiabetic and obese only/ } \\
\text { diabetic only }\end{array}$ & \multirow[t]{2}{*}{$\begin{array}{l}P \\
\text { (univariate) }\end{array}$} \\
\hline & $\begin{array}{l}n(\%) / \text { mean } \pm \text { SD } \\
(n=623)\end{array}$ & $\begin{array}{l}n(\%) / m e a n \pm S D \\
(n=3,868)\end{array}$ & \\
\hline Male & $343(55.1)$ & $2,473(63.9)$ & $<0.001$ \\
\hline Female & $280(44.9)$ & $\mathrm{I}, 395(36.1)$ & $<0.001$ \\
\hline Age, mean $\pm S D$ & $71.12 \pm 10.02$ & $70.55 \pm 15.31$ & 0.23 \\
\hline Age $\geq 75$ years & $225(36.1)$ & $1763(45.6)$ & $<0.001$ \\
\hline Dialysis duration, mean $\pm S D$ & $3.91 \pm 4.2$ & $6.01 \pm 7.19$ & $<0.001$ \\
\hline Registration on RT waiting list & $55(8.8)$ & $566(14.6)$ & $<0.001$ \\
\hline $\begin{array}{l}\text { Reason for nonregistraion on the RT list (medically } \\
\text { contra indicated) }\end{array}$ & $348(55.9)$ & $1,669(43.2)$ & $<0.001$ \\
\hline Dialysis modality (in-center dialysis) & $423(67.9)$ & $2,283(59.0)$ & $<0.001$ \\
\hline Smoking & $54(8.7)$ & $521(13.5)$ & 0.005 \\
\hline \multicolumn{4}{|l|}{ Method of dialysis } \\
\hline Hemodialysis & $597(95.8)$ & $3,678(95.1)$ & 0.42 \\
\hline Peritoneal dialysis & $26(4.2)$ & $190(4.9)$ & 0.42 \\
\hline \multicolumn{4}{|l|}{ Comorbidities } \\
\hline CVD & $465(74.6)$ & $2,462(63.7)$ & $<0.001$ \\
\hline COPD & $124(19.9)$ & $481(12.4)$ & $<0.001$ \\
\hline Cancer & $49(7.9)$ & $453(11.7)$ & 0.004 \\
\hline Coronary insufficiency & $272(43.7)$ & $481(12.4)$ & $<0.001$ \\
\hline Cardiac insufficiency & $154(24.7)$ & $846(21.9)$ & 0.11 \\
\hline Myocardial infarction & 73 (1I.7) & $401(10.4)$ & 0.32 \\
\hline Cerebrovascular accident & $78(12.5)$ & $405(10.5)$ & 0.14 \\
\hline Cardiac arrhythmia & $186(29.9)$ & $\mathrm{I}, 072(27.7)$ & 0.28 \\
\hline Arteritis of the lower limbs & $210(33.7)$ & $\mathrm{I}, 032(26.7)$ & $<0.001$ \\
\hline Cirrhosis & $7(1.1)$ & $59(1.5)$ & 0.432 \\
\hline Hepatitis B & $4(0.6)$ & $44(1.1)$ & 0.262 \\
\hline Hepatitis C & $9(1.4)$ & $94(2.4)$ & 0.125 \\
\hline
\end{tabular}

Abbreviations: RT, renal transplant; COPD, chronic obstructive pulmonary disease; CVD, cardiovascular disease.

Comorbidities and Other Characteristics among Obese-Diabetic, NonobeseNondiabetic, and Obese Only/Diabetic Only Patients

Table 3 presents the results of the multinomial regression analysis.

The analysis revealed different profiles between our reference group, i.e,obese-diabetic, and the two comparison groups:nonobese-nondiabetic and diabetic only ( $p<0.001$ and $p<0.05$, respectively). On the other hand, there was no significant difference in comparison with the third group i.e obese only $(p>0.05)$.

Patients in the nonobese-nondiabetic group showed many differences from the obese-diabetic group. They were older, with a higher proportion of patients aged $>75$ years (OR, $2.40 p<0.001)$. There were fewer women (OR $0.63, p<0.001$ ) than the obese-diabetic group (Table 3).

These patients were more likely to be on the waiting list for a kidney transplant (OR 2.33,p<0.001) and less likely to be followed up in centers for dialysis (OR 0.69, $p<0.05)$ than obese-diabetic patients with ESRD.

In addition, they had fewer comorbidities, and there were fewer cases of COPD (OR 0.53, $p<0.001$ ), coronary insufficiency (OR 0.49, $p<0.001$ ), CVD (OR 0.70, $<<0.05$ ), and arteritis of the lower limb (OR $0.68, p<0.05$ ). On the other hand, they were more likely to have cancer (OR 1.78, $p<0.05$ ) and to smoke (OR 2.36, $p<0.001$, Table 3).

Compared to our reference group (diabetic-obese), patients in the diabetes-alone group were older, ie, $>75$ years of age (OR 2.09, $p<0.001$ ). They were also more likely to be on the waiting list for a kidney transplant 
Table 2 Multivariate analysis of associated comorbidities and other characteristics of ESRD patients on RRT

\begin{tabular}{|c|c|c|c|c|}
\hline & $\begin{array}{l}\text { Group I, } \\
\text { obese- } \\
\text { diabetic }\end{array}$ & $\begin{array}{l}\text { Group } 2 \text {, } \\
\text { nonobese-nondiabetic and obese onlyl } \\
\text { diabetic only }\end{array}$ & OR & $\begin{array}{l}P \\
\text { (multivariate) }\end{array}$ \\
\hline \multicolumn{5}{|l|}{ Comorbidities } \\
\hline CVD & $74.6 \%$ & $63.7 \%$ & $\begin{array}{l}\text { OR } 1.38,95 \% \mathrm{Cl} \\
1.04-1.83\end{array}$ & 0.028 \\
\hline Coronary insufficiency & $43.7 \%$ & $12.4 \%$ & $\begin{array}{l}\text { OR } 1.49,95 \% \mathrm{Cl} \\
\text { I.19-1.87 }\end{array}$ & 0.001 \\
\hline COPD & $19.9 \%$ & $12.4 \%$ & $\begin{array}{l}\text { OR } 1.75,95 \% \mathrm{Cl} \\
1.36-2.24\end{array}$ & $<0.001$ \\
\hline Cancer & $7.8 \%$ & $11.7 \%$ & $\begin{array}{l}\text { OR } 0.68,95 \% \mathrm{Cl} \\
0.49-0.95\end{array}$ & 0.024 \\
\hline \multicolumn{5}{|l|}{ Other variables } \\
\hline Age $\geq 75$ years & $36.1 \%$ & $45.6 \%$ & $\begin{array}{l}\text { OR } 0.46,95 \% \mathrm{Cl} \\
0.38-0.57\end{array}$ & $<0.001$ \\
\hline Smoking & $8.7 \%$ & $13.5 \%$ & $\begin{array}{l}\text { OR } 0.5 \mathrm{I}, 95 \% \mathrm{Cl} \\
0.36-0.7 \mathrm{I}\end{array}$ & $<0.001$ \\
\hline $\begin{array}{l}\text { Dialysis modality (in-center } \\
\text { dialysis) }\end{array}$ & $67.9 \%$ & $59.0 \%$ & $\begin{array}{l}\text { OR } 1.29,95 \% \mathrm{Cl} \\
1.05-1.59\end{array}$ & 0.014 \\
\hline $\begin{array}{l}\text { Registration on renal transplant } \\
\text { waiting list }\end{array}$ & $8.8 \%$ & $14.6 \%$ & $\begin{array}{l}\text { OR } 0.46,95 \% \mathrm{Cl} \\
0.33-0.65\end{array}$ & $<0.001$ \\
\hline
\end{tabular}

Abbreviations: CVD, cardiovascular disease; COPD, chronic obstructive pulmonary disease.

(OR 1.92,p<0.05). As observed in the nonobese-nondiabetic group, there were also fewer women in this group (OR $0.58, p<0.001$ ). Furthermore, fewer of them had COPD (OR 0.56, $<<0.001)$ despite the fact that more of them smoked (OR 1.48, $p<0.05$ ).

Finally, the model showed no significant differences for the obese-only group (Table 3).

\section{Discussion}

This study analyzed comorbidity profiles among obesediabetic ESRD patients in the REIN registry of PACA region of France. To our knowledge, there is no study that has analyzed comorbidity in an obese-diabetic ESRD cohort, and few studies have been carried out on ESRD and CKD cohorts.

We found that four comorbidities were associated significantly with obese-diabetic ESRD patients by performing multivariate analysis through binary logistic regression (Table 2). To strengthen the results retrieved through our first model, we decided to divide the data into four groups, and we used the second model, ie, multinomial logistic regression, to compare these four groups. Five comorbidities were found to be significantly associated with obese-diabetic ESRD patients by multinomial regression analysis (Table 3 ). The numbers of associated comorbidities were lower than our expectations, although many of the comorbidities were significant on univariate analysis (Table 1). We were not able to find a study that analyzed comorbidity profiles in obese-diabetic ESRD patients, and that is why we cannot compare our results with another study on the same topic. Comorbidities are often associated to a large degree with ESRD patients, depending on age, region, education, and quality of life. Increasing age, obesity, diabetes, CVD, hypertension, and poor nutrition are important coexisting conditions that predict the worst outcomes for patients with ESRD. Of these, CVDs are highly associated with morbidity and mortality in the ESRD population.

The prevalence of such comorbidities as obesity, diabetes mellitus, and hypertension were found to be markedly high in CKD patients in a descriptive prospective 


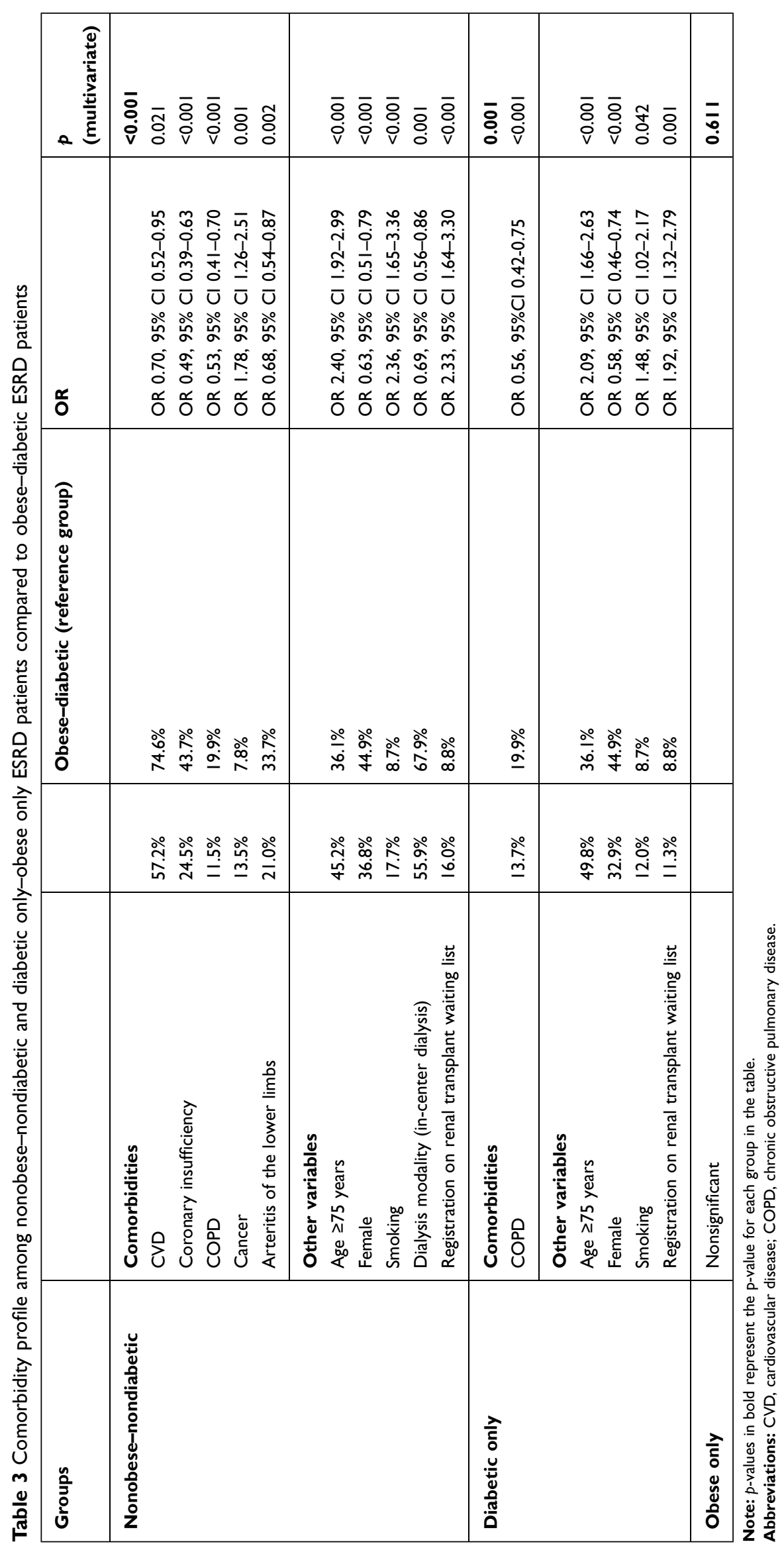


study carried out in a Nigerian tertiary kidney care hospital analyzing the comorbidity profile among 123 CKD patients. ${ }^{27}$ In our study, we also found that obesity and diabetes were associated with 2,243 ESRD patients on dialysis, and in addition our sample was much larger than the study carried out in Nigeria.

To find which group contained the younger patients, we set an age limit of $\geq 75$ years. We found that the obesediabetic patients were younger than their obese-only, diabetic only, and nonobese-nondiabetic counterparts in both analyses.

We also observed that the majority of the obese-diabetic patients were receving dialysis at centers than the other groups. The major reason behind this may have been special care and management and the satisfaction of these patients (Tables 2 and 3). In accordance with the literature, ESRD patients on dialysis aged $\geq 80$ years have a satisfactory quality of life and no more complications than younger ESRD patients, despite many comorbidities. ${ }^{28}$ In a comparative study comparing comorbidities and their contribution to mortality between the registry of a clinical setting and a state-based registry, similar comorbidities in the two registries were found, and it was concluded that the comorbidities found in the two registries had the similar predictive ability, irrespective of the origin of the dataset. Although the study was limited to five comorbidities, all were significant predictors of poor survival in all four models. ${ }^{29}$ We also observed that obese-diabetic patients were less likely to be on the renal transplant waiting list (Tables 2 and 3). This reflects the fact that there is an increased chance of graft rejection in obese patients compared to the nonobese, and obese patients are often directed to lose weight to a certain level before renal transplantation to inhibit graft rejection.

According to a 2013-2014 UK Renal Registry report, the most common comorbid conditions found in incident ESRD patients on RRT were diabetes mellitus (36\%) and ischemic heart disease (20\%). Comorbidities in diabetic ESRD patients were higher than in nondiabetics. These included ischemic heart disease ( $28.3 \%$ vs $14.8 \%)$, COPD (8.6\% vs $6.6 \%)$, smoking (13.4\% vs $12.5 \%)$, and cancer (9.6\% vs $15.4 \%$ ) for diabetic and nondiabetic ESRD patients, respectively. ${ }^{33}$ Compared to the UK Renal Registry report, our results also showed a greater percentage of comorbidities with obese-diabetic ESRD patients on RRT. It is necessary to mention here that our patients were obese alongwith diabetes, but in the case of the UK Renal Registry, the patients were diabetic only. Interestingly, cancer was recorded less in diabetic ESRD patients in the UK Renal Registry, and the same was found in our study. On the other hand, there were more smokers among the diabetic ESRD patients in the UK Renal Registry report, and the same was noted in our multinomial regression analysis for diabetic ESRD patients (Table 3 ), while we noted fewer smokers in our binary logistic regression analysis in obese-diabetic patients than the other group ( $8.7 \%$ vs $13.5 \%)$ in our study (Table 2 ).

Vital contributors to CKD load are the growing frequency of obesity, diabetes, and hypertension, which are well-established risk factors of CKD and ESRD. Public health-care policies directed at addressing lifestyle factors that contribute to these conditions are expected to mitigate CKD risk. ${ }^{34}$ Population-wide interventions to control obesity may have more beneficial effects in preventing the development or delaying the progression of CKD. ${ }^{35}$

In addition, among patients with mild-moderate CKD, patient awareness of diagnosis is poor. CKD progression and complications are clearly influenced by dietary and lifestyle choices and management of comorbid conditions like diabetes, dyslipidemia, and hypertension. Improving patient awareness and providing patient education (low-sodium diet, quitting smoking, losing weight if overweight, and tight control of blood-pressure and blood-sugar levels) will help patients manage their chronic disease andl lead to better outcomes. ${ }^{36}$

Both diabetes and obesity along with hypertension contribute highly to the development and progression of KD and hypertension, if not treated may lead to ESRD. Although early intervention and management of body weight, hypertension, and hyperglycemia are highly recommended, novel therapeutic measures are also necessary to minimize the high morbidity and mortality associated with obesity and diabetes-related $\mathrm{KD}^{6}{ }^{6}$

Our study has revealed comorbidity profiles among obese-diabetic ESRD patients in the REIN registry of PACA region. The results of both models used for analysis in this study confirmed that obesity and diabetes are the driving forces for comorbidities in ESRD patients. The strength of this study was the large number of patients and the completeness of the collected data, while a limitation of our study was the inclusion of a single French region that had certain characteristics, such as more oldage ESRD patients and fewer peritoneal dialysis patients than other regions. Furthermore, we selected those ESRD patients who already had two comorbidities, ie, obesity and diabetes. Due to this specificity, we found fewer patients for this study than expected. In addition, fewer 
cardiovascular comorbidities were noted significant on multivariate analysis.

The novelty of our study is of great importance, as we believe that no such analysis has been carried out before, ie, including obese-diabetic ESRD patients for analysis of comorbidities. Another study on the same topic from a registry of a different region will certainly help in understanding regional similarities, differences, and the number of associated comorbidities in these patients.

\section{Conclusion}

In this study, comorbidity profiles revealed that cardiovascular comorbidities, including coronary insufficiency along with COPD, were significantly associated with obese-diabetic ESRD patients in the PACA region of France. In addition, obese-diabetic ESRD patients smoked less, were younger, but less likely to be on the renal transplant waiting list. We suggest regular health education and awareness training by health-care professionals to minimize the risk of comorbidities in these patients.

\section{Ethics Approval and Consent to Participate}

All subjects involved in this study were taken from the French REIN registry under an agreement with the CNIL (Commission Nationale de l'Information et des Libertés; 903188 version 6). The study was approved by the CNIL and the confidentiality of all collected information ensured. Verbal informed consent was obtained from all subjects to participate in the study.

\section{Acknowledgments}

The authors would like to thank Dr Niamatullah Kakar, Dr Habib Ur Rehman Kakar, and Borhane Ferkak for their efforts and contribution to this study. Asmatullah Kakar is funded by the Higher Education Commission (HEC) of Pakistan.

\section{Author Contributions}

All authors contributed significantly to the work reported, including conception and design of the study, execution, data acquisition, data analysis and interpretation, drafting the manuscript, and revising and critically reviewing the article. All authors have read and approved the final version to be published, have agreed on the journal to which the article has been submitted, and agree to be accountable for all aspects of the work.

\section{Disclosure}

The authors declare that they have no conflicts of interest.

\section{References}

1. Les données du rapport REIN 2018. France: REIN. Available from: https://www.francerein.org/actualites/23-les-donnees-du-rapport-rein. Accessed September 4, 2020.

2. United States Renal Data System. 2019 USRDS annual data report: epidemiology of kidney disease in the United States. Bethesda, MD: National Institutes of Health, National Institute of Diabetes and Digestive and Kidney Diseases; 2019. Available from: https://www. usrds.org/annual-data-report/. Accessed October 6, 2020.

3. Stengel B, Billon S, Van Dijk PCW, et al. Trends in the incidence of renal replacement therapy for end-stage renal disease in Europe, 1990-1999. Nephrol Dial Transplant. 2003;18(9):1824-1833. doi:10.1093/ndt/gfg233

4. Kramar R, Oberbauer R. Austrian dialysis and transplantation registry (OEDTR). Аnпи Rep. 2005.

5. Mallamaci F, Tripepi G. Obesity and CKD progression: hard facts on fat CKD patients. Nephrol Dial Transplant. 2013;28(Suppl 4):iv105108. doi:10.1093/ndt/gft391

6. Maric-Bilkan C. Obesity and diabetic kidney disease. Med Clin North Am. 2013;97(1):59-74. doi:10.1016/j.mcna.2012.10.010

7. Lindeman RD, Tobin J, Shock NW. Longitudinal studies on the rate of decline in renal function with age. J Am Geriatr Soc. 1985;33 (4):278-285. doi:10.1111/j.1532-5415.1985.tb07117.x

8. Ritz E, Orth SR. Nephropathy in patients with type 2 diabetes mellitus. $N$ Engl J Med. 1999;341(15):1127-1133. doi:10.1056/ NEJM199910073411506

9. Adler AI, Stevens RJ, Manley SE, et al. Development and progression of nephropathy in type 2 diabetes: the United Kingdom prospective diabetes study (UKPDS 64). Kidney Int. 2003;63(1):225-232. doi:10.1046/j.1523-1755.2003.00712.x

10. Young JH, Klag MJ, Muntner P, Whyte JL, Pahor M, Coresh J. Blood pressure and decline in kidney function: findings from the systolic hypertension in the elderly program (SHEP). J Am Soc Nephrol JASN. 2002;13(11):2776-2782. doi:10.1097/01.asn.0000031805.09178.37

11. Haroun MK, Jaar BG, Hoffman SC, Comstock GW, Klag MJ, Coresh J. Risk factors for chronic kidney disease: a prospective study of 23,534 men and women in Washington County, Maryland. J Am Soc Nephrol JASN. 2003;14(11):2934-2941. doi:10.1097/01. asn.0000095249.99803.85

12. Kramer H, Luke A, Bidani A, Cao G, Cooper R, McGee D. Obesity and prevalent and incident CKD: the hypertension detection and follow-up program. Am J Kidney Dis. 2005;46(4):587-594. doi:10.1053/j.ajkd.2005.06.007

13. Gelber RP, Kurth T, Kausz AT, et al. Association between body mass index and CKD in apparently healthy men. Am J Kidney Dis. 2005;46 (5):871-880. doi:10.1053/j.ajkd.2005.08.015

14. Ejerblad E, Fored CM, Lindblad P, et al. Association between smoking and chronic renal failure in a nationwide population-based casecontrol study. J Am Soc Nephrol JASN. 2004;15(8):2178-2185. doi:10.1097/01.ASN.0000135048.35659.10

15. Orth SR. Effects of smoking on systemic and intrarenal hemodynamics: influence on renal function. $J$ Am Soc Nephrol JASN. 2004;15(Suppl 1):S58-63. doi:10.1097/01.asn.0000093461.36097.d5

16. Pinto-Sietsma SJ, Mulder J, Janssen WM, Hillege HL, de Zeeuw D, de Jong PE. Smoking is related to albuminuria and abnormal renal function in nondiabetic persons. Ann Intern Med. 2000;133(8):585591. doi:10.7326/0003-4819-133-8-200010170-00008

17. Barnett K, Mercer SW, Norbury M, Watt G, Wyke S, Guthrie B. Epidemiology of multimorbidity and implications for health care, research, and medical education: a cross-sectional study. Lancet Lond Engl. 2012;380(9836):37-43. doi:10.1016/S0140-6736(12)60240-2 
18. Durand A-C, Jouve E, Delarozière J-C, et al. End-stage renal disease treated in Provence-Alpes Côte d'Azur: 12-years follow-up and forecast to the year 2030. BMC Nephrol. 2018;19(1):141. doi:10.1186/ s12882-018-0929-y

19. Mahmoodi BK, Matsushita K, Woodward M, et al. Associations of kidney disease measures with mortality and end-stage renal disease in individuals with and without hypertension: a meta-analysis. Lancet Lond Engl. 2012;380(9854):1649-1661. doi:10.1016/S0140-6736 (12)61272-0

20. Fox CS, Matsushita K, Woodward M, et al. Associations of kidney disease measures with mortality and end-stage renal disease in individuals with and without diabetes: a meta-analysis. Lancet Lond Engl. 2012;380(9854):1662-1673. doi:10.1016/S0140-6736(12)61350-6

21. Jesky M, Lambert A, Burden ACF, Cockwell P. The impact of chronic kidney disease and cardiovascular comorbidity on mortality in a multiethnic population: a retrospective cohort study. BMJ Open. 2013;3(12):e003458. doi:10.1136/bmjopen-2013-003458

22. Gallacher KI, Batty GD, McLean G, et al. Stroke, multimorbidity and polypharmacy in a nationally representative sample of $1,424,378$ patients in Scotland: implications for treatment burden. BMC Med. 2014;12:151. doi:10.1186/s12916-014-0151-0

23. Tonelli M, Muntner P, Lloyd A, et al. Using proteinuria and estimated glomerular filtration rate to classify risk in patients with chronic kidney disease: a cohort study. Ann Intern Med. 2011;154(1):12-21. doi:10.7326/0003-4819-154-1-201101040-00003

24. Manley HJ, Cannella CA, Bailie GR, St Peter WL. Medicationrelated problems in ambulatory hemodialysis patients: a pooled analysis. Am J Kidney Dis off J Natl Kidney Found. 2005;46(4):669-680. doi:10.1053/j.ajkd.2005.07.001

25. Mason NA, Bakus JL. Strategies for reducing polypharmacy and other medication-related problems in chronic kidney disease. Semin Dial. 2010;23(1):55-61. doi:10.1111/j.1525-139X.2009.00629.x

26. Cardone KE, Bacchus S, Assimon MM, Pai AB, Manley HJ. Medication-related problems in CKD. Adv Chronic Kidney Dis. 2010;17(5):404-412. doi:10.1053/j.ackd.2010.06.004
27. Fasipe OJ, Akhideno PE, Owhin SO, Ilukho FA, Ibiyemi-Fasipe OB. The comorbidity profile among chronic kidney disease patients in clinical practice: a prospective study. Int Arch Health Sci. 2019;6 (1):46-51. doi:10.4103/iahs.iahs 21 18

28. Leimbach T, Kron J, Pommer W, Urbach B, Kron S. Comorbidities, hospitalization, and living status of dialysis patients over 80 years. Blood Purif. 2016;42(4):282-286. doi:10.1159/000448210

29. Kotwal S, Webster AC, Cass A, Gallagher M. Comorbidity recording and predictive power of comorbidities in the Australia and New Zealand dialysis and transplant registry compared with administrative data: 2000-2010. Nephrology. 2016;21(11):930-937. doi:10.1111/nep.12694

30. Prasad N, Gupta A, Sinha A, et al. Confounding effect of comorbidities and malnutrition on survival of peritoneal dialysis patients. $J$ Ren Nutr. 2010;20(6):384-391. doi:10.1053/j.jrn.2010.01.001

31. Agence de la biomédecine. Available from: https://www.agence-bio medecine.fr/. Accessed October 12, 2020.

32. Couchoud C, Stengel B, Landais P, et al. The renal epidemiology and information network (REIN): a new registry for end-stage renal disease in France. Nephrol Dial Transplant. 2006;21(2):411-418. doi:10.1093/ndt/gfi198

33. Steenkamp R, Caskey F. UK Renal Registry 18th annual report: chapter 6 comorbidities and current smoking status amongst patients starting renal replacement therapy in England, Wales and Northern Ireland from 2013 to 2014. Nephron. 2016;132(Suppl. 1):145-154. doi:10.1159/000444820

34. Luyckx VA, Tuttle KR, Garcia-Garcia G, et al. Reducing major risk factors for chronic kidney disease. Kidney Int Suppl. 2017;7(2):7187. doi:10.1016/j.kisu.2017.07.003

35. Kovesdy CP, Furth S, Zoccali C. World kidney day steering committee. Obesity and kidney disease: hidden consequences of the epidemic. Physiol Int. 2017;104(1):1-14. doi:10.1556/2060.104.2017.1.9

36. Management of chronic kidney disease. Available from: http://www. med.umich.edu/1 info/FHP/practiceguides/kidney/CKD.pdf. Accessed October 4, 2020

Diabetes, Metabolic Syndrome and Obesity: Targets and Therapy

Dovepress

\section{Publish your work in this journal}

Diabetes, Metabolic Syndrome and Obesity: Targets and Therapy is an international, peer-reviewed open-access journal committed to the rapid publication of the latest laboratory and clinical findings in the fields of diabetes, metabolic syndrome and obesity research. Original research, review, case reports, hypothesis formation, expert opinion and commentaries are all considered for publication. The manuscript management system is completely online and includes a very quick and fair peer-review system, which is all easy to use. Visit http://www.dovepress.com/testimonials.php to read real quotes from published authors.

Submit your manuscript here: https://www.dovepress.com/diabetes-metabolic-syndrome-and-obesity-targets-and-therapy-journal 